\title{
Pyridoxin Deficiency in the Rat: Liver L-Cysteic Acid Decarboxylase Activity and Urinary Amino-acids
}

\author{
By H. BLASCHKO \\ Department of Pharmacology, University of Oxford \\ S. P. DATTA \\ Department of Biochemistry, University College, London \\ AND H. HARRIS \\ The Galton Laboratory and Department of Biochemistry, \\ University College, London
}

(Received 28 May 1953)

A recent survey of the urinary amino-acids of various animals (Datta \& Harris, I95 I, I953) has shown taurine to be present in the urine of some species, e.g. the mouse, rat and dog, but absent from others, e.g. the guinea-pig, cow and rabbit; the occurrence of taurine in cat's urine is irregular.

Some time ago an enzyme was described that liberates carbon dioxide from L-cysteic acid under anaerobic conditions (Blaschko, 1942). This enzyme occurs in the liver of the dog and the rat, but it has not been found in some other species, e.g. the cat. The product of the decarboxylation had not been identified, but the amount of carbon dioxide formed-one mole of $\mathrm{CO}_{2}$ for one mole of L-cysteic acid addedsuggested that it was taurine:

$$
\begin{aligned}
& \mathrm{HSO}_{3} \cdot \mathrm{CH}_{2} \cdot \mathrm{CH}\left(\mathrm{NH}_{2}\right) \cdot \mathrm{COOH} \rightarrow \mathrm{HSO}_{3} \cdot \mathrm{CH}_{2} \cdot \mathrm{CH}_{2} \cdot \mathrm{NH}_{2}+\mathrm{CO}_{2} \text {. } \\
& \text { cysteic acid taurine }
\end{aligned}
$$

Extracts from the livers of rats reared on a diet deficient in pyridoxin have very little or no L-cysteic acid decarboxylase activity (Blaschko, Carter, O'Brien \& SloaneStanley, I948). It seemed of interest therefore to examine the urinary amino-acids and liver L-cysteic acid decarboxylase activity of pyridoxin-deficient rats, particularly as in normal rats taurine is the principal ninhydrin-reacting substance in the urine. The present paper describes such an investigation.

\section{EXPERIMENTAI}

Diet. The diet was similar to that used by Carpenter, Harris \& Kodicek (1948-9), poor in protein and containing succinylsulphathiazole. Its percentage composition was as follows:

$\begin{array}{lcll}\text { Casein } & 10 \cdot 5 & \text { L-cystine } & 0.15 \\ \text { Sucrose } & 80 \cdot 35 & \text { Arachis oil } & 3 \cdot 0 \\ \text { Salt mixture } & 5 \cdot 0 & \text { Succinylsulphathiazole } & \text { I.0 } \\ \text { (Steenbock no. 40) } & & & \end{array}$


Each animal received the following supplements:

Daily
I $\mu \mathrm{g}$ biotin
$30 \mu \mathrm{g}$ thiamine
$30 \mu \mathrm{g}$ riboflavin
$200 \mu \mathrm{g}$ calcium pantothenate
$250 \mu \mathrm{g}$ nicotinic acid
$20 \mathrm{mg}$ choline chloride

Three times weekly $40 \mu \mathrm{g}$ folic acid in $1 \% \mathrm{KH}_{2} \mathrm{PO}_{a}$

Once weekly

I drop of a $5 \%$ solution of tocopherol acetate 4 drops cod-liver oil

I mg menaphthone

The animals receiving this diet are called pyridoxin-deficient animals; the 'plus pyridoxin' controls received a daily supplement of $3 \circ \mu \mathrm{g}$ pyridoxin.

Animals. These were piebald rats obtained from Glaxo Laboratories; they were newly weaned and were given the experimental diet on arrival in the laboratory; their weights were then $25-32 \mathrm{~g}$. Either whole litters were given the deficient diet with other litters as 'plus pyridoxin' controls or litters were divided, some animals being given the deficient diet and their litter-mates the 'plus pyridoxin' diet.

Collection and chromatography of urines. The animals were placed on wire-netting overnight, either singly or in pairs. Some of the deficient animals were very weak and died during the period of urine collection. Urine (10 $\mu 1$.) was run on twodimensional paper chromatograms $(20 \times 20 \mathrm{~cm})$, phenol and collidine-lutidine being the solvents (Datta, Dent \& Harris, 1950).

Determination of enzyme activity. The animals were killed after their urine had been collected. The livers were dissected out, weighed and thoroughly ground in a mortar that had been cooled to $-\mathrm{I} 2^{\circ}$, and $\mathrm{I} \mathrm{ml}$. $0.067-\mathrm{M}$ sodium phosphate buffer, $\mathrm{pH} 7 \cdot 4$, was added for each gram of liver. The suspension formed was centrifuged at $600 \mathrm{~g}$ for $5 \mathrm{~min}$, the supernatant fluid being used for manometric experiments. The method of determining $q_{\mathrm{CO}_{2}}$ was that described by Sloane-Stanley (1949). The $\mathrm{L}$-cysteic acid $-q_{\mathrm{CO}_{2}}$ is defined as the number of $\mu$ l. of $\mathrm{CO}_{2}$ formed by $\mathrm{I} \mathrm{mg}$ tissue (fresh weight)/h. In a few experiments, when the livers of the deficient animals were very small, the livers of two rats were pooled for preparing the extract.

\section{RESULTS}

General. The animals receiving the pyridoxin-deficient diet gained weight at first, but after 12-14 days the weight curves of the deficient animals began to rise less steeply than those of the 'plus pyridoxin' controls; after the end of the $3^{\text {rd week on }}$ the deficient diet the animals showed little further gain in weight, and a loss of weight often occurred. Fig. I shows the growth curves of a litter of animals of which five were maintained on the deficient and four on the control diet. The coats of the deficient animals were generally in a poorer condition than those of the controls: skin lesions were often present, but were usually mild; the forepaws and the snout were often affected, the hind-paws and the tail less frequently.

The body-weights of the 'plus pyridoxin' controls continued to rise, often at a uniform rate, throughout the experiment; thus a considerable difference in bodyweight between the control and the deficient animals developed and became more marked with time. To eliminate the possibility that differences between animals on 
the deficient diet and the control diet were due to differences in body-weight, two different groups of animals on the control diet were examined. In the first group were animals kept on the control diet for the same length of time as the deficient animals on the deficient diet, in the second group were animals kept on the control diet until they had attained approximately the same body-weight as the deficient animals. In the first group therefore the control animals were heavier than the deficient animals whereas in the second group they were younger.

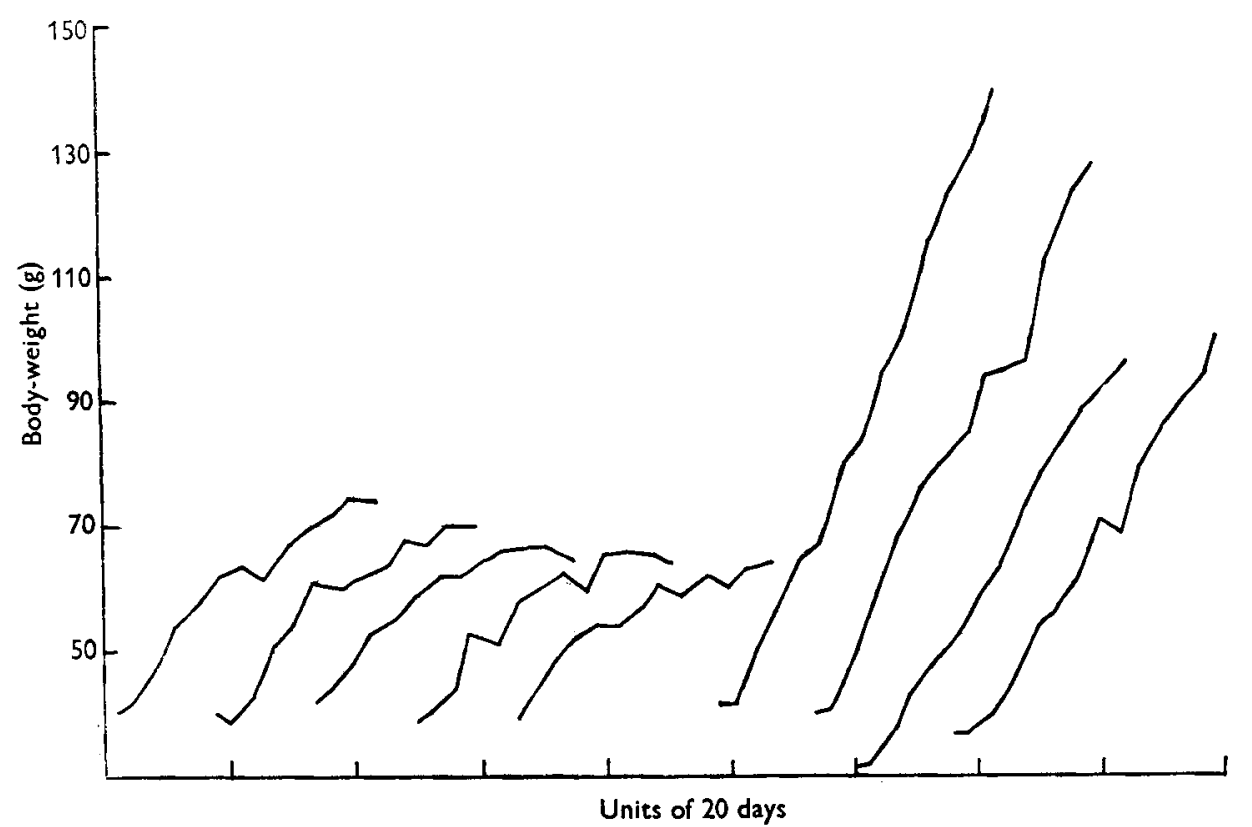

Fig. I. Growth curves of a litter of nine animals. The five curves on the left relate to animals on the pyridoxin-deficient diet; the four curves on the right relate to animals on the control diet.

The results of the urine chromatography are set out in Table $\mathrm{x}$. Only the occurrence of taurine and a substance provisionally identified as ethanolamine phosphate in the urine chromatograms is recorded, as these were the principal ninhydrin-

Table I. Taurine and ethanolamine phosphate in urine samples from pyridoxin-deficient and normal control rats

\begin{tabular}{|c|c|c|c|c|c|c|}
\hline \multirow[b]{2}{*}{$\begin{array}{l}\text { Group } \\
\text { no. }\end{array}$} & \multirow[b]{2}{*}{$\begin{array}{l}\text { No. of } \\
\text { animals }\end{array}$} & \multicolumn{3}{|c|}{ 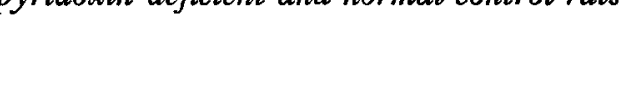 } & \multicolumn{2}{|c|}{$\begin{array}{l}\text { No. of urine } \\
\text { samples containing }\end{array}$} \\
\hline & & Days on diet & $\begin{array}{l}\text { Mean body-weight } \\
\text { (and its standard error) } \\
\text { (g) }\end{array}$ & $\begin{array}{l}\text { No. of } \\
\text { samples } \\
\text { examined }\end{array}$ & Taurine & $\begin{array}{l}\text { Ethanol- } \\
\text { amine } \\
\text { phosphate }\end{array}$ \\
\hline \multicolumn{7}{|c|}{ Diet with pyridoxin } \\
\hline I & $\begin{array}{r}12 \\
7\end{array}$ & $\begin{array}{r}9-27 \\
36-37\end{array}$ & $\begin{array}{l}46 \cdot 4( \pm 0 \cdot 74) \\
88 \cdot 0( \pm 4 \cdot 26)\end{array}$ & $\begin{array}{l}7 \\
7\end{array}$ & $\begin{array}{l}\text { All } \\
\text { All }\end{array}$ & $\begin{array}{l}1 \\
0\end{array}$ \\
\hline \multicolumn{7}{|c|}{ Diet without pyridoxin } \\
\hline $\begin{array}{l}3 \\
4\end{array}$ & $\begin{array}{l}18 \\
19\end{array}$ & $\begin{array}{l}27-30 \\
33-47\end{array}$ & $\begin{array}{l}42 \cdot 2( \pm 1 \cdot 15) \\
45 \cdot 8( \pm 1 \cdot 87)\end{array}$ & $\begin{array}{l}16 \\
14\end{array}$ & $\begin{array}{l}7 \\
2\end{array}$ & $\begin{array}{l}15 \\
\text { All }\end{array}$ \\
\hline
\end{tabular}


reacting substances seen. Glycine, alanine and occasionally other amino-acids were detected, but these were always present at much lower concentrations and their amounts were very variable. Fig. 2 shows typical urine chromatograms of a deficient and a control animal. The substance provisionally identified as ethanolamine phosphate has the same $R_{F}$ values in phenol (0.33), collidine-lutidine (0.09) (Dent, 1948) and butanol-acetic acid-pyridine (0.33) as ethanolamine phosphate. Further, this spot is stable to oxidation with hydrogen peroxide and is only partially destroyed by hydrolysis in $6 \mathrm{~N}-\mathrm{HCl}$ for $24 \mathrm{~h}$ at $100^{\circ}$ (Dent, I948).

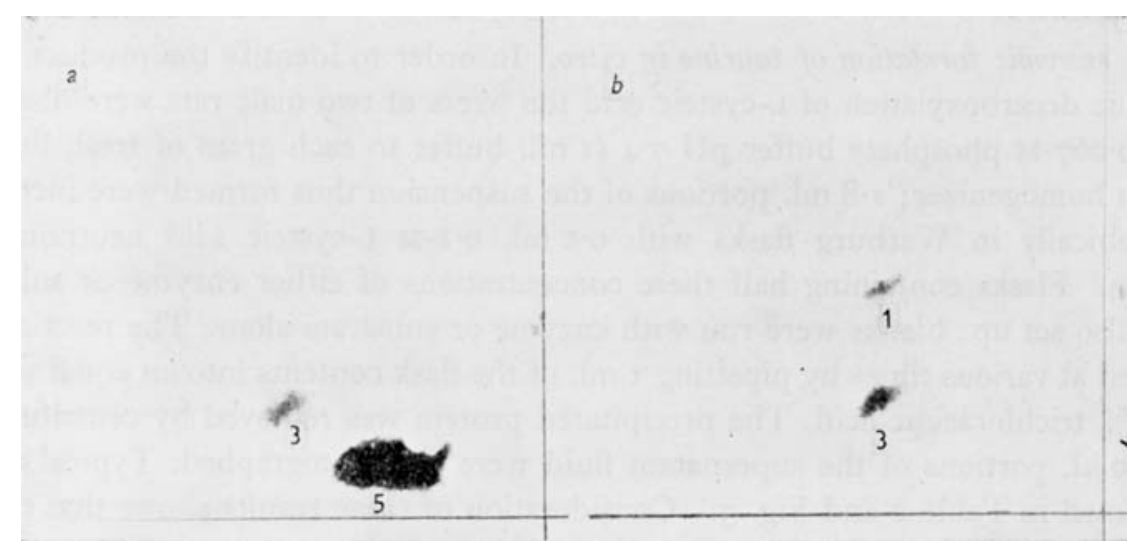

Fig. 2. Chromatograms of $10 \mu$ l. urine applied at the lower right-hand corner of the squares; phenol was run horizontally to the left and collidine-lutidine vertically upwards. $a$, urine from a pyridoxindeficient animal; $b$, urine from an animal on the control diet. $r$, taurine; 3 , glycine; 5 , "ethanolamine phosphate'.

'Plus pyridoxin' control animals. It will be seen from Table I that fourteen samples of urine from nineteen control animals were examined. In group $\mathrm{I}$ were animals on the control diet for 9-27 days, their final body-weights being 42-52 g; from this group there were seven urine samples, of which five were pooled samples from pairs of animals. In group 2 the animals had been on the control diet for $3^{6}$ or 37 days, their final body-weights being between 67 and $104 \mathrm{~g}$; a urine sample was obtained from each animal. Taurine was present in all these urine samples, and 'ethanolamine phosphate' was seen in only one of them.

The L-cysteic acid decarboxylase activity of the livers of these control animals was determined; in only four (three females) was it insignificant. The mean $q_{\mathrm{CO}_{2}}$ for the twelve males was 0.95 , while for the seven females it was 0.07 ; the lower activity in the livers of females is in accord with findings of Sloane-Stanley (1949).

Pyridoxin-deficient animals. Altogether thirty-seven deficient animals were examined; thirty urine samples were obtained, seven being pooled samples from pairs of animals. In group 3 of Table $I$ were animals kept on the deficient diet for 3 o days or less, their final body-weights being 36-49 g; taurine was present in seven out of sixteen urine samples, and 'ethanolamine phosphate' was found in all but one. Group 4 were animals kept on the deficient diet for 33-47 days, their final body-weights being 
34-66 g; taurine was found in only two out of fourteen urine samples, and 'ethanolamine phosphate' was present in all of them.

The L-cysteic acid decarboxylase activity was determined in the livers of those animals in groups 3 and 4 that survived the urine collection; in all the nineteen samples (including two pooled extracts from pairs of animals) there was no significant enzymic activity.

Two animals reared on a riboflavin-deficient diet were examined by similar methods; both urines contained taurine, but no 'ethanolamine phosphate' or any other ninhydrin-reacting substance, and both the livers showed L-cysteic acid decarboxylase activity.

The enzymic formation of taurine in vitro. In order to identify the product of the enzymic decarboxylation of L-cysteic acid the livers of two male rats were dispersed with 0.067 -M phosphate buffer $\mathrm{pH} 7.4$ ( $\mathrm{r}$ ml. buffer to each gram of fresh liver) in a glass homogenizer; $1.8 \mathrm{ml}$. portions of the suspension thus formed were incubated anaerobically in Warburg flasks with $0.2 \mathrm{ml}$. $0 . \mathrm{I}-\mathrm{M}$ L-cysteic acid neutralized to $\mathrm{pH} 7 \cdot 4$. Flasks containing half these concentrations of either enzyme or substrate were also set up; blanks were run with enzyme or substrate alone. The reaction was stopped at various times by pipetting I ml. of the flask contents into an equal volume of $20 \%$ trichloracetic acid. The precipitated protein was removed by centrifugation and $10 \mu$ l. portions of the supernatant fluid were chromatographed. Typical results are shown in Table 2 and Fig. 3. Consideration of these results shows that taurine

Table 2. Chromatographic identification of amino-acids after incubation of a rat-liver preparation with cysteic acid

Rat-liver enzyme (ml.)
L-cysteic acid
Time of incubation (min)
$\mathrm{CO}_{2}$ produced $(\mu \mathrm{l}$.
Calculated percentage of L-cysteic
acid decarboxylated
Chromatographically identified
Cysteic acid
Taurine
Glycine
Glutamic and aspartic acids
Other amino-acids
Chromatogram on Fig. 3

\begin{tabular}{lccc} 
I.8 & 0.9 & I.8 & I.8 \\
$0.01 \mathrm{M}$ & $0.01 \mathrm{M}$ & $0.0 \mathrm{IM}$ & 0 \\
0 & 135 & 270 & 270 \\
0 & 47 & 362 & 0 \\
0 & 10.5 & 80.8 & 0 \\
& & & \\
+++ & ++ & Trace & - \\
Trace & + & +++ & Trace \\
Trace & + & ++ & ++ \\
Trace & + & ++ & ++ \\
\multicolumn{1}{c}{$a$} & Trace & + & + \\
& $b$ & $c$ & $d$
\end{tabular}

appears in the chromatogram as the cysteic acid disappears, these changes being in agreement with those expected from the results for the evolution of $\mathrm{CO}_{2}$. The appearance of glycine, glutamic and aspartic and other amino-acids seen in the preparations that had been incubated is presumably due to the autolysis of the liver protein. There was a trace of taurine detectable in the preparations that had not been incubated; this did not appear to increase on incubation of the liver suspension alone, whereas the great increase in taurine and decrease in cysteic acid when the liver suspension and substrate had been incubated together leave no room for doubt that taurine is in fact produced by the enzymic decarboxylation of L-cysteic acid. 


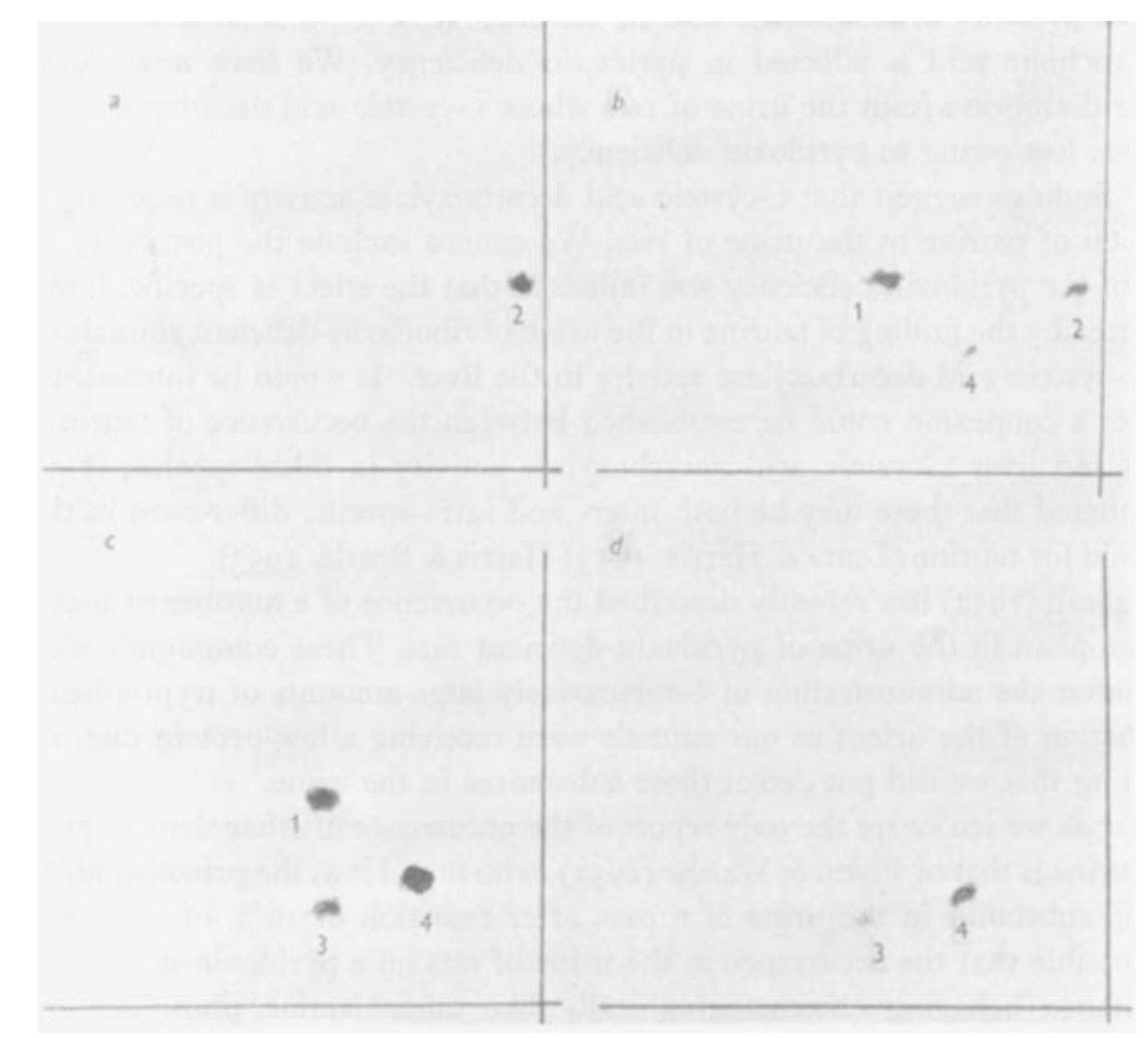

Fig. 3. Chromatograms showing the enzymic formation of taurine in vitro. 10 $\mu 1$. of the protein-free reaction mixture were applied at the lower right-hand corner of the squares; phenol was run horizontally to the left and collidine-lutidine vertically upwards. For details see Table 2. I, taurine; 2, cysteic acid; 3 , glycine; 4, glutamic acid.

\section{DISCUSSION}

The results shown in Table I confirm the earlier observations (Datta \& Harris, 195 I, 1953) that taurine is a normal constituent of rat's urine. Taurine disappears from the urine of rats deficient in pyridoxin, the disappearance being complete only after the animals have received the deficient diet for 30-35 days. The earlier findings that pyridoxin deficiency leads to a disappearance of the liver L-cysteic acid decarboxylase activity (Blaschko et al. 1948 ) are also confirmed.

The pathways of taurine biosynthesis in the mammalian organism are not fully known. Until recently it was thought that taurine occurred only in a conjugated form in the taurocholic acid of the bile, but it is now known to be widely distributed in the free state in animal tissues (Walker, 1952). Cysteic acid has been considered a possible precursor of taurine, and we have now confirmed that the enzyme L-cysteic acid decarboxylase is able to convert cysteic acid to taurine. The enzyme, however, could not be demonstrated in some species in which conjugated taurine is found in the bile (Blaschko, 1942).

There is at present no evidence to connect the occurrence of taurine in the urine 
with the presence of taurocholic acid in the bile. It is also unknown if the excretion of taurocholic acid is affected in pyridoxin deficiency. We have now shown that taurine disappears from the urine of rats whose L-cysteic acid decarboxylase activity has been lost owing to pyridoxin deficiency.

Our findings suggest that L-cysteic acid decarboxylase activity is necessary for the excretion of taurine in the urine of rats. We cannot exclude the possibility that the effect of the pyridoxin deficiency was indirect; that the effect is specific, however, is supported by the finding of taurine in the urine of riboflavin-deficient animals together with L-cysteic acid decarboxylase activity in the liver. It would be interesting to see whether a connexion could be established between the occurrence of taurine in the tissues and liver L-cysteic acid decarboxylase activity in other species; it must be remembered that there may be both inter- and intra-specific differences in the renal threshold for taurine (Datta \& Harris, I953; Harris \& Searle, 1953).

Dalgliesh (1952) has recently described the occurrence of a number of metabolites of tryptophan in the urine of pyridoxin-deficient rats. These compounds were only found after the administration of comparatively large amounts of tryptophan before examination of the urine; as our animals were receiving a low-protein diet, it is not surprising that we did not detect these substances in the urine.

As far as we are aware the only report of the occurrence of ethanolamine phosphate in the urine is that of Flynn \& Walshe (1951), who found it as the principal ninhydrinreacting substance in the urine of a man after resection of $16 \%$ of his liver. It is thus possible that the occurrence in the urine of rats on a pyridoxin-deficient diet of a substance behaving chromatographically like ethanolamine phosphate may be associated with changes in the liver, of which the decrease in L-cysteic acid decarboxylase activity is a reflexion. On the other hand, it may be that the disturbance of fat metabolism associated with pyridoxin deficiency (Carter \& Phizackerley, 195I) may lead to an accumulation of this substance in the blood, with consequent excretion in the urine. Further work is required to confirm if this ninhydrin-reacting substance is in fact ethanolamine phosphate; in view of the susceptibility of this ester to phosphatases, it would be of interest to examine the distribution of these enzymes in pyridoxin-deficient animals.

\section{SUMMARY}

I. Taurine was found to be present in the urine of rats on a normal diet, but disappeared from the urine of rats on a pyridoxin-deficient diet.

2. The liver L-cysteic acid decarboxylase activity disappeared in rats on a pyridoxindeficient diet.

3. It has been shown that liver L-cysteic acid decarboxylase converts L-cysteic acid into taurine and carbon dioxide.

4. The connexion between the urinary excretion of taurine and the liver L-cysteic acid decarboxylase activity is discussed.

5. A substance provisionally identified as ethanolamine phosphate has been found in the urine of rats on a pyridoxin-deficient diet; it was absent from the urine of the animals on a 'plus pyridoxin' control diet. 


\section{REFERENCES}

Blaschko, H. (1942). Biochem. F. 36, 57 1.

Blaschko, H., Carter, C. W., O'Brien, J. R. P. \& Sloane-Stanley, G. H. (1948). Y. Physiol. ro7, 18 P.

Carpenter, K. J., Harris, L. J. \& Kodicek, E. (1948-9). Brit. F. Nutr, 2, vii.

Carter, C. W. \& Phizackerley, P. J. R. (195I). Biochem. F. 49, 227.

Dalgliesh, C. E. (1952). Biochem. F. 52, 3 .

Datta, S. P., Dent, C. E. \& Harris, H. (1950). Science, IIz, 621.

Datta, S. P. \& Harris, H. (195r). Э. Physiol. rr4, $39 P$.

Datta, S. P. \& Harris, H. (1953). Ann. Eugen., Lond., r8, 107.

Dent, C. E. (1948), Biochem. F. 43, 169.

Flynn, F. V. \& Walshe, J. M. (195I). Brit. med. F. i, I484.

Harris, H. \& Searle, A. G. (1953). Ann. Eugen., Lond., 17, 165.

Sloane-Stanley, G. H. (1949). Biochem. F. 45, 556.

Walker, D. M. (1952). Biochem. F. 52, 679. 